\title{
Prevalence and predictors of unsolicited exposure to and involvement in online sexual activites among young Internet users in Lagos metropolis
}

\author{
Kunnuji, Michael O.N. (Ph.D.) \\ Department of Sociology, University of Lagos, Akoka - Yaba, Lagos, Nigeria \\ e-mail:nuunayt@yahoo.com; michaelkunnuji@gmail.com; mkunnuji@unilag.edu.ng
}

\begin{abstract}
The study draws empirical evidence from adolescents (aged 10 to 19 years) and young adults (20 to 24 years) who use the Internet in exploring the relationship between two sets of independent variables - background characteristics and context of Internet use and two sets of dependent variables - unsolicited exposure to online materials with sexual contents, and involvement in online sexual activities. The background characteristics explored in the study are age, sex, autonomy (whether living alone or with parents), access to funds and parent-child communication, while the Internet use context variables are place of access, all-night Internet use and intensity of use. The study reveals that close to half of the subjects had been involved in at least one online sexual activity with intensity and time of Internet use as the strongest predictors of involvement.
\end{abstract}

Keywords: Online pornography; unsolicited exposure; online sexual activities; youth sexuality; context of Internet use

\section{Introduction}

The last quarter of the 20th century witnessed the birth and rapid diffusion of the Internet. This technology is used (or misused) in all spheres of life, from very informal social relations such as chats to issues relating to political economy, freedom, human rights and discourse on the essence of the modern state. Put differently, the Internet has become a very central part of living and it shapes how people relate with one another. In Nigeria, there are I5.9 Internet users per 100 people (United Nations, 2010). By implication, more than 25 million Nigerians use the Internet. Yet, there is an unequal representation of people of different age groups among Internet users in the country. Young people within the age bracket of 10 to 24 years constitute the largest proportion of Internet users (Kunnuji, 2010). This is because they far outnumber adults in the population and adapt better and faster to new technologies than adults. Persons below the age of 10 on the other hand are far less likely to use the Internet due to their lower level of literacy, computeracy and access to the Internet. Therefore, a study of Internet users in Nigeria is largely a study of young people. Collins et al. (2010) agree that adolescents are very much involved with new media, although there appears to be no evidence regarding the impact of the media on their real behaviours. While the relationship between exposure to and involvement in online sexual activities and real life sexual behaviour may not have been established, Dombrowski et al. (2007) argue that since children use the Internet in an atmosphere that can expose them to inappropriate sexual materials, there is a need to provide them with education and protection.

To further stress the need for a study of young people's exposure to and involvement in online sexual activities, a study by Rambaree (20I I) points out that adolescents in Mauritius are involved in cybersex and the Internet breaks down the traditional and moral values of the society, as young people are becoming exposed to new and foreign sexual mores through the technology. This gives credence to the need raised by Dombrowski et al. (2007) for education and protection. In order to provide the required protection, it is important to know the nature of the use to which young people put the Internet in relation to accessing materials with sexual content.

\section{Literature review and theoretical framework}

The use of online text, audio, and graphic materials for achieving sexual stimulation/pleasure and/or for acquiring sexual knowledge has attracted the attention of several researchers. In addition to the use of the Internet for sexual activities, some researchers have also considered unwanted or unsolicited exposure to materials with sexual contents online. Finkelhor et al. (2000) found that 25 percent of the adolescents they sampled had been exposed to webbased pornography, even when they were not planning to do so, and 20 percent had received sexual solicitation online. Wolak et al. (2007) showed that forty-two percent of young Internet users had been 
exposed to online pornography in the previous one year preceding their study. Among these youths, two-thirds reported that they had been exposed to online pornography without seeking to access such materials.

Several studies have documented factors associated with exposure to and involvement in online sexual activities. Some studies have shown that as adolescents grow up, their use of the Internet becomes more complex and their willing involvement in romantic activities increases, the implication being that they are more vulnerable to Internet -initiated sex crimes (Wolak et al. 2004; Subrahmanyam et al. 2006; Wolak et al. 2008). Another study, by Barbovschi (2009), supports this position. The researcher shows that with age comes a greater involvement in online-offline dating and more frequent and complex use of the Internet. Boyd and Marwick (2009) also agree to this position. These studies suggest that age is a factor in online sexual activities. Very young adolescents are to be expected, therefore, to be less exposed to and involved in online sexual activities.

Other studies have sought to show the relationship between real life and online sexual activities. McFarlene et al. (2002) found that young adults involved in online sexual activities are more sexually active than those who do not take part in sexual activities online. Similarly, a study by Pardun et al. (2005) shows that exposure to sexual content in the media is significantly related to adolescents' sexual activities and future intentions to be sexually active. Adolescents who reported a high level of media exposure to sexual content also reported a high level of sexual activities and intentions to be sexually active in the future. It is possible to conclude from these studies that involvement in online sexual activities is associated with real life sexual activities and vice versa. It is in fact possible that both are caused by an extraneous factor not measured in the studies. Nonetheless, these studies have established that the variables are associated.

Some researchers have explored the role of gender in exposure to materials with sexual content and involvement in online sexual activities. Mitchell et al. (2007) found through a survey that females who had close online relationships and took part in online sexual activities reported a greater level of receiving requests for a sexual picture than males. Requests for pictures with sexual connotations, however, constitute one form of exposure to sexual content online; there are several others, such as receiving links to pornographic sites and finding oneself at pornographic sites without intending to. It is important therefore to explore the degree to which gender determines exposure to sexual content online using these other indicators. Viewing the role of gender from a different dimension, Subrahmanyam et al. (2006) found that females are more implicit in their communication of sexual content than male adolescents online. This observation is expected to manifest in more willing involvement among young males than females in online sexual activities such as sending mails with sexual content and visiting pornographic sites.

Other researchers argue that involvement in online sexual activities among young people is caused by factors such as prolonging adolescence ${ }^{1}$ (Arnett, 2000), preoccupation with self-definition ${ }^{2}$ (Freeman-Long, 2000; Longo et al. 2002), and the desire by young people to find answers to their numerous unanswered questions on matters of sexuality (Longo et al. 2002). Young people who do not participate in online sexual activities were found to be more satisfied with themselves in offline matters; they maintained better connections with their friends and families (Boies et al. 2004). This finding suggests that young people with an identity crisis and those who feel dissatisfied with their real life relationships are more likely to be involved in online sexual activities. Another factor associated with exposure to online pornography is the place of access, with adolescents who use the Internet at friends' homes more likely to willingly seek pornography online (Wolak, Mitchell and Finkelhor, 2007). This shows that peers may have a strong influence on one another.

Studies have documented the real-life sexual activities of young people in Nigeria. A national survey shows that about $4 \mathrm{I}$ percent and 84 percent of young females within the age brackets of 15-19 years and 20-24 years respectively had experienced penetrative sexual intercourse at the time of the study (Federal Ministry of Health [Nigeria], 2006). Among boys within the age brackets of 15-19 and 20-24 years, 20 percent and 63 percent respectively had experienced penetrative sexual intercourse, while 35 percent and 73 percent of sexually experienced girls within the age brackets of 15-19 years and 20-24 years had been involved in premarital sex in the 12 months preceding the study (Federal Ministry of Health [Nigeria], 2006). In addition, the study found that 15 percent of boys within the $15-19$ age group had had sex in the last 12 months and 53 percent of young men within the age bracket of 20-24 years had had sex in the last 12 months. Among sexually experienced youths (15-19 years), eight percent had contracted STIs in the 12 months preceding the survey. For the 20-24 age group, 10 percent had contracted an STI (Federal Ministry of Health [Nigeria], 2006). Studies have also shown that risky sexual activities such as multiple sexual partnerships 
and unprotected sex are not uncommon within this population (WHO, 200I).

Despite the rising proportion of young people with access to the Internet in Nigeria, very little is known about young people's exposure to and involvement in online sexual activities. In an urban centre like Lagos, the likelihood of having access to the Internet is further increased by the proliferation of cybercafés. This study is concerned with providing an answer to a central question, which is Among young Internet users in Lagos metropolis, what is the prevalence of exposure to and involvement in online sexual activities?' Put differently, to what extent do young people take part in activities aimed at achieving sexual stimulation and/or gratification or collecting information on sexuality related matters? It is important to have empirical evidence to support any claims concerning the involvement of young people in online sexual activities as well as on how pervasive such activities are. Further, an understanding of the factors that are associated with exposure to and involvement in online sexual activities will also be of great benefit to planners of reproductive health and human sexuality related programmes as well as researchers, as this will contribute to the body of knowledge on young people's sources of information on sexuality related matters. For this reason the study seeks to examine the relationship between background characteristics such as age, sex, access to money, autonomy (whether they are living alone or with parents/adult care givers) and parent-child communication (PCC) and the variables of exposure to and involvement in online sexual activities. In addition, the effect of factors within the context of Internet use such as place of access, time of use (with emphasis on day-only usage versus all-night usage) and regularity of use on exposure and involvement in online sexual activities is examined in this study.

Figure I depicts the interrelationships among the various variables of interest. The independent variables are categorised under background characteristics (i.e. age, sex, autonomy and access to money) and context of Internet use (i.e. time of use, with emphasis on all-night Internet use and place of access). The dependent variables as shown in Figure $\mathrm{I}$ are unsolicited exposure to sexual material online and involvement in online sexual activities with specific indicators listed below them. The study aims to show how background characteristics are associated with unsolicited exposure to sexual content online as well as involvement in online sexual activities. It also seeks to explore the links between Internet use context variables on the one hand, and unsolicited exposure to sexual contents and involvement in online sexual activities on the other. It is expected that background characteristics will have some influence on context of Internet use variables just as unsolicited exposure to sexual content online may be associated with involvement in online sexual activities. This study explores the web of interconnectedness among the variables shown in the schema.

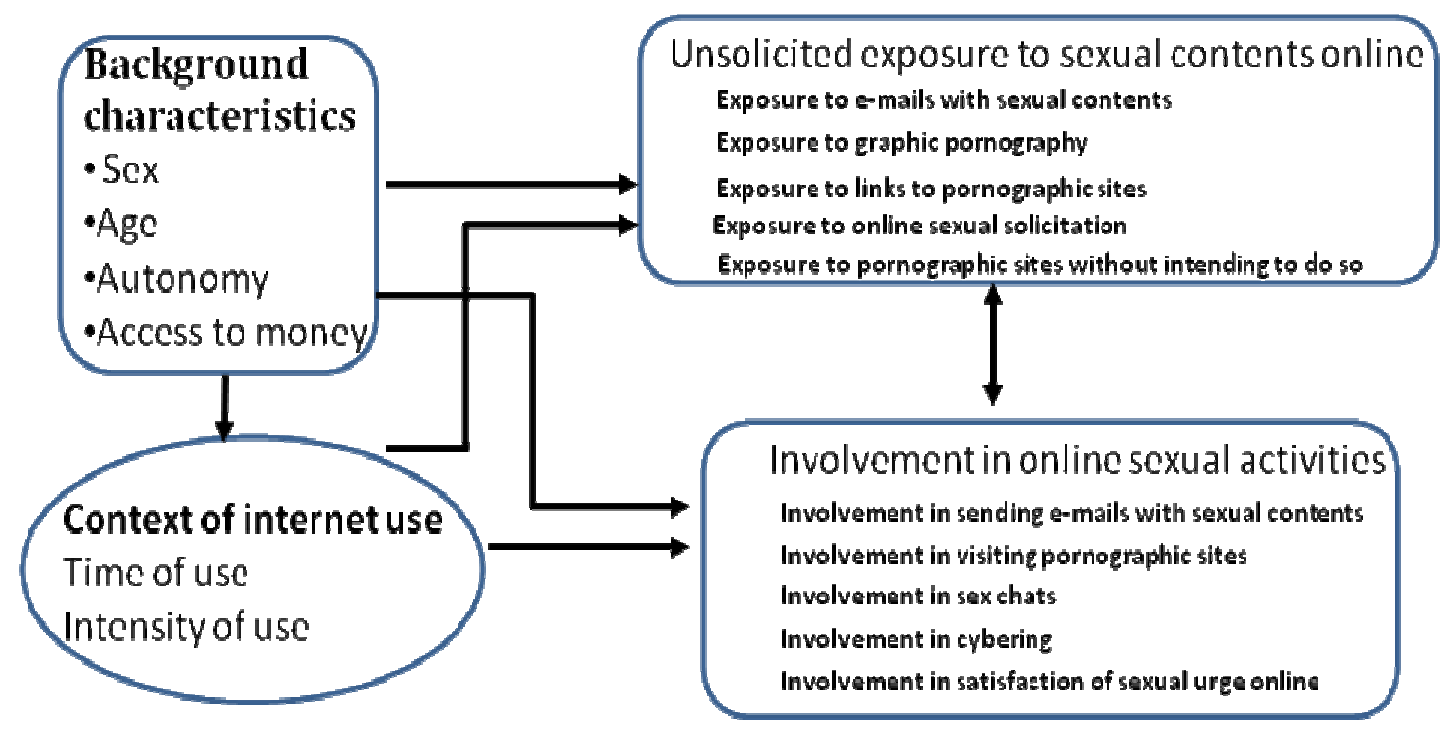

Figure 1: Model showing key predictors of exposure to and involvement in online sexual activities 


\section{Data and methods}

Data used for this study were drawn from a larger survey of I I 20 participants, including young users of the Internet and non-users of the Internet in Lagos metropolis. The proposed sample for the survey was I 200 participants, of whom I I 20 were successfully interviewed. Participants in this study include 648 young users of the Internet within the age bracket of 10-24 years resident in Lagos metropolis, Nigeria. The respondents were selected through a multistage sampling exercise in which five Local Government Areas (LGAs) were randomly selected out of the 16 LGAs that make up the Lagos metropolis. The LGAs included in the study are Ajeromi-Ifelodun, Surulere, Lagos Mainland, Shomolu and Ifakoljaye, all in the Lagos metropolis. From each selected LGA, streets were listed and sampled randomly while households were systematically selected before eligible respondents were randomly drawn. A map of streets in the city of Lagos was used to create the list of streets (see West African Book Publishers, 2004). A fifth of the proposed sample size was allocated to each of the LGAs. A listing of the LGAs revealed that none of them had fewer than 16 residential streets. Therefore, 15 households were selected from 16 streets across the LGAs and one respondent was selected from each household. The sampling intervals range from three to eleven. In the street with the smallest number of houses, one in every three houses was included in the survey, while in the street with the largest number of houses, one in eleven houses was included in the study. The proportions of houses sampled range from a third to less than ten percent. The criteria for inclusion in the study are: age (only adolescents aged 10-19 years and young adults aged 20-24 years were eligible); Internet use (only persons who said they had ever used the Internet were eligible); residence (only young people resident in Lagos metropolis were eligible); and consent (i.e. a stated willingness to be part of the study). Informed consent was sought and obtained from adolescents 18 years and above, while parental assent was obtained for adolescents below the age of 18 in addition to consent from the participants before interviews were conducted. All interviews were held outside hearing distance of third parties and only successful interviews (i.e. interviews in which usable (internally consistent) answers were obtained on the core concerns of the study) were processed for analysis using the Statistical Package for Social Sciences. The selected participants excluded do not differ significantly from those excluded in terms of background characteristics.

\section{Procedure}

A standardised interview schedule containing ques- tions on respondents' background information, access to and use of the Internet, exposure to materials with sexual content and involvement in online sexual activities was administered to the subjects in face-to-face interviews. Only responses from respondents who supplied usable answers to key questions were processed for analysis. The validation of the instrument was done through expert review. The study design and research instruments were subjected to institutional review at two levels, the first being a departmental postgraduate board of studies comprising sociologists, demographers and social research methodologists, and the second a university postgraduate board of studies comprising faculties from across the humanities. The instrument was pre-tested on a sample of 120 respondents (not included in the actual survey); the scores for the different items indicative of exposure to materials with sexual content and involvement in online sexual activities correlated significantly.

\section{Measures}

The independent variables in this study fall under two broad categories. The first is the category of background characteristics. These are age (in years), sex (male or female), access to money (measured by the subject's allowance or earnings in the last month), and autonomy (measured by living arrangement: with parents/other adult care givers versus living alone). Another background feature measured in the study is parent-child communication on matters of sexuality. This is also measured in the binary form with subjects who reported having benefited from parent-child communication constituting one category, and those who had not benefited from PCC constituting the other. The second set of independent variables includes factors in the context of Internet use. These include the place of Internet use, with users of the Internet who access the Internet at home and school constituting one category, and subjects who access the Internet at cybercafés, friends' homes and other places constituting another category. Intensity of Internet use was measured through the regularity of use. Subjects who access the Internet weekly were categorised as frequent users, while those who access the Internet less often were categorised as occasional users. The last variable explored under the Internet use context factors is the time of Internet use. This measure creates two categories of users, namely subjects who use the Internet during the day as well as all night; and subjects who use the Internet during the day only.

The dependent variables in this study are unsolicited exposure to materials with sexual content and involvement in online sexual activities. Five questionnaire items address unsolicited exposure to materi- 
als with sexual content. These items are designed to measure exposure in binary form. Specifically, the items document: (i) receipt of e-mails with sexual content in text form; (ii) receipt of e-mails with pornographic pictures; (iii) receipt of mails with links to sites containing pornography in text or pictorial form; (iv) receipt of e-mails with sexual solicitation; and (v) arriving at websites with materials containing sexual messages without intending to do so. These variables are measured at the nominal level. The study measures involvement in online sexual activities using five questionnaire items which are later converted into one composite measure at the multivariate analysis level. The questionnaire items employed in the measurement of involvement in online sexual activities are binary in form. The items measure involvement in: (i) the sending of e-mails with sexual content; (ii) visiting pornographic sites; (iii) involvement in sex chats; (iv) involvement in online sex which may involve the use of webcam and/or online telephone services in a manner that arouses the subject sexually; (v) satisfaction of sexual desire online through any of items i-iv. The composite measure of involvement in online sexual activities is a measure of involvement in any one of the items listed. This is also measured as a binary nominal variable.

\section{Analysis}

The analysis employs simple frequencies and percentages in the description of the subjects, their exposure to information related to sexuality, and involvement in online sexual activities. Pearson's chisquare test was employed in establishing whether age, sex, autonomy, parent-child communication, time of Internet use, place of access, intensity and access to funds are associated with exposure to sexually explicit information and involvement in online sexual activities. The composite measure of involvement in online sexual activity was employed in running a logistic regression test to show the predictive power of the independent variables on the dependent variables. Involvement in online sexual activities was coded "I" and abstinence from all online sexual activities measured in the study was coded "0". Similarly, having ever been exposed to sexuality related information online without seeking such information was coded "I", while no unsolicited exposure was coded " 0 ". For all the tests conducted, significance is accepted at $\mathrm{P}<0.0$ I or 0.05 .

\section{Results}

As stated earlier, the study included youths within the age bracket of 10 to 24 years. A little above 46 percent of all the subjects interviewed had been involved in one or more online sexual activities, with males recording a significantly higher rate of involvement than young female Internet users. Generally, the study puts access to the Internet at about 62 percent among the participants, while 58 percent were users of the Internet at the time of the study. Most (5I percent) of the young Internet users studied spend exactly one hour each time they get connected to the Internet. A little over 25 percent spend two hours online on each occasion of using the Internet; 12 percent spend 30 minutes on each occasion; five percent spend three hours while two percent spend an average of four hours on each occasion of Internet use. Four percent of the subjects spend five hours or more online on each occasion of using the Internet. The concentration of young Internet users in the 'one hour category' is not difficult to understand. Many who would love to spend more time online are constrained financially. Charges per hour begin from NI00.00 (\$0.64). In addition, in some cybercafés, the minimum period that can be paid for is one hour, while in others paying for an hour or more attracts some rebate in comparison with paying for 30 minutes. The rebates could be as high as $20 \%$ off the cost per hour. Some of the cafés offer services that allow for long hours (up to five hours) of Internet access with huge rebates.

In addition to Internet usage during the day, some (27 percent of the participants) use the Internet all night. Often, two or three all night users pay for all night use and share the time between/among themselves, the result being that the actual duration of Internet use for a typical all night Internet user on each occasion of getting connected is less than five hours. All night use, the study reveals, gives greater room for anonymity and because there are usually fewer users, speed is gained and so, users can do more of whatever they choose to do. The study also shows that purposes of all-night Internet usage include chatting, school assignments and research, filling in of examination forms, business, games and cybering. The execution of school assignments was mentioned as the reason for all-night Internet use by $2 \mathrm{I}$ percent of the adolescents; chatting with friends was mentioned by 43 percent; research was mentioned by 13 percent, while six percent mentioned the filling in of examination forms. Another six percent mentioned business. In summary the study shows that a typical young Internet user (using the median value) in the Lagos metropolis is one who gets connected to the Internet three times weekly and stays online for one hour on each occasion.

\section{Unsolicited exposure to materials with sexual content}

About 43 percent of the subjects said they had received e-mails with sexual content in text form; 45 
percent had received e-mails with sexually explicit or suggestive pictures; 44 percent had received emails with links to sites with sexually explicit information; 36 percent had been asked for sexual inti- macy online while 44 percent had arrived at websites with sexual content without intending to do so.

Table I Unintended exposure to sexually explicit information online by background characteristics (\%)

Ever received Ever received Ever received Ever experienced Ever mail with mail containing mail with links online sexual reached a textual sexual graphic to sexually solicitation site with content pornography explicit sites sexual messages without intending to do so

\begin{tabular}{|c|c|c|c|c|c|c|}
\hline Sex & Male $(\mathrm{N}=368)$ & $46.7^{*}$ & 48.9* & $50.3 * *$ & 33.2 & 46.7 \\
\hline & Female $(\mathrm{N}=280)$ & 38.9 & 38.9 & 34.6 & 38.6 & 39.6 \\
\hline \multirow[t]{3}{*}{ Age } & $10-14$ yrs $(\mathrm{N}=18)$ & II.I** & $22.2 * *$ & $22.2^{*}$ & $22.2 * *$ & $\mathrm{II} . \mathrm{I}^{*}$ \\
\hline & $15-19$ yrs $(\mathrm{N}=226)$ & 36.3 & 38.9 & 39.4 & 27.0 & 41.6 \\
\hline & $20-24$ yrs $(\mathrm{N}=404)$ & 48.8 & 48.8 & 46.8 & 40.8 & 46.3 \\
\hline \multirow[t]{2}{*}{ Autonomy } & Living alone $(\mathrm{N}=62)$ & 61.3** & $58 . I^{*}$ & 54.8 & $50.0 *$ & $29.0 *$ \\
\hline & Living with parents (586) & 41.5 & 43.2 & 42.3 & 34.0 & 16.9 \\
\hline \multirow[t]{2}{*}{ PCC } & Enjoyed PCC ( $\mathrm{N}=487)$ & 43.1 & $41.9 *$ & $41 . I^{*}$ & 34.9 & 42.3 \\
\hline & Never enjoyed PCC $(\mathrm{N}=16 \mathrm{I})$ & 44.1 & 52.8 & 50.9 & 37.3 & 47.8 \\
\hline \multirow[t]{2}{*}{ Time of use } & All night user ${ }^{\mathrm{a}}(\mathrm{N}=174)$ & $65.5 * *$ & $66.7 * *$ & $63.2 * *$ & $53.4 * *$ & $58.0 * *$ \\
\hline & Day only user $(\mathrm{N}=474)$ & 35.2 & 36.5 & 36.3 & 28.9 & 38.4 \\
\hline \multirow{2}{*}{$\begin{array}{l}\text { Place of } \\
\text { access }\end{array}$} & Home and/or school $(\mathrm{N}=152)$ & 42.8 & 47.4 & 44.1 & 38.2 & 42.8 \\
\hline & Café and other places $(\mathrm{N}=496)$ & 43.5 & 43.8 & 43.3 & 34.7 & 44.0 \\
\hline \multirow{2}{*}{$\begin{array}{l}\text { Frequency of } \\
\text { use }\end{array}$} & Regular user $(\mathrm{N}=426)$ & $49.5 * *$ & $50.2 * *$ & 49.3** & $40.4 * *$ & $47.4^{*} *$ \\
\hline & Occasional user $(\mathrm{N}=222)$ & 31.5 & 33.8 & 32.4 & 26.1 & 36.5 \\
\hline \multirow{3}{*}{$\begin{array}{l}\text { Access to } \\
\text { money }\end{array}$} & None $(\mathrm{N}=60)$ & $41.7 * *$ & $41.7^{*}$ & $41.7 * *$ & $36.7 * *$ & $38.3 * *$ \\
\hline & Less than $\mathrm{NI} 0,000(\mathrm{~N}=35 \mathrm{I})$ & 36.2 & 40.5 & 37.9 & 28.5 & 39.0 \\
\hline & $\mathrm{NI} 0,000$ or more $(\mathrm{N}=237)$ & 54.4 & 51.5 & 52.3 & 45.6 & 51.9 \\
\hline \multicolumn{2}{|l|}{ All $(\mathbf{N}=648)$} & 43.4 & 44.6 & 43.5 & 35.5 & 43.7 \\
\hline
\end{tabular}

$* \rightarrow p<0.05$; ** $\rightarrow p<0.01$; a - Participants categorised as "All night Internet users" include those who get connected at night (between 10:00 pm and 6:00 am), but may also use the Internet during the day while the "Day only users" do not use the Internet all night at all.

As shown in Table I, gender is associated with receipt of e-mails with sexual text, pictures and links to sites with sexually explicit information, but not with sexual solicitation and finding oneself at a website with sexually explicit information without intending to do so. Generally, young males reported greater exposure to sexually explicit information than young females. Females reported greater experience of sexual solicitation, however, although the relationship is not statistically significant. The data further reveal that age is associated with all identified indicators of unsolicited exposure to sex related materials. Exposure to sex related materials increases with age, as shown in Table I. A good example is the receipt of e-mails with sexual content in the form of text. While just II percent of early adolescent subjects (10-14 years) had received this type of e-mail, 36 percent of Late adolescent sub- 
jects (15-19 years), and 49 percent of Young adult subjects (19-24 years) had received such mails. Similar observations were made on other indicators of unsolicited exposure to sex related information.

The study also shows that there is an association between living arrangements (i.e. with parents or alone), an indicator of autonomy and all but one of the indicators of exposure to sex related materials. Young people living alone reported greater exposure to sex related information than those living with their parents. Furthermore, it shows that PCC is significantly associated with the receipt of e-mails with pictures suggestive of sex and links to sites with sexually explicit information, but not with other indicators of exposure to sexually explicit information online. Time of Internet use was found to be associated with all indicators of exposure to sexually explicit information online. Young people who use the Internet "all night" reported greater exposure to e-mails with sexual text, pictures, links to sites with sexually explicit sites, sexual solicitation and accessing sites with sexual content without intending to do so. Place of access on the other hand has no significant relationship with exposure to sexually explicit information online. Frequency of Internet use is associated with online exposure to sexually explicit information. As shown in Table I, regular users of the Internet reported greater exposure to sexually explicit information than occasional users.

The study also shows that having access to money (monthly allowance or wages) is associated with exposure to sex related information online. While more than half of the subjects with an average monthly allowance of $\mathrm{N} 10,000.00$ or more reported exposure to four of the five indicators of exposure to sex related information, just about 36 percent of the subjects who received less than N10 000.00 reported receiving e-mails with text discussing sex; 41 percent reported receipt of e-mails with explicit pictures; 38 percent had received mails with links to sexually explicit sites; 29 percent had received emails with sexual solicitation; and 39 percent had found themselves at websites with sexual content without intending to do so. Those without access to monthly allowances were found to be similar to those with little allowance on several of the indicators of exposure to sexually explicit information online. In summary, the study has shown that all night Internet use, high frequency of Internet use, access to money and age are associated with online exposure to sex related information.

The logistic regression model in Table 2 further shows that the most significant predictors of exposure to unsolicited sexuality related information are the time of Internet use, intensity of Internet use and access to money. Young people involved in all-night Internet use are more likely to be exposed to unsolicited pornography than young people who use the Internet during the day only. The study further shows that young people who use the Internet regularly are more likely to be exposed to Internet pornography than occasional users of the Internet. Furthermore, young people with low monthly incomes are less likely to experience unsolicited exposure to information on sexuality.

Table 2 Logistic regression predicting likelihood of unintended exposure to sexually explicit information online among adolescent Internet users

\begin{tabular}{llll}
\hline Variables & B & S.E & Odds ratio \\
\hline Time of Internet use & & & \\
\hline Involved in all night use (ref. cat.) & - & - & 1.0 \\
\hline Day only user & $-I .015$ & 0.278 & $0.362^{* * * *}$ \\
\hline & & & \\
\hline Intensity of use & & & \\
\hline Regular users (ref. cat.) & - & - & 1.0 \\
\hline Occasional users & -0.557 & 0.219 & $0.573^{*}$ \\
\hline
\end{tabular}

\begin{tabular}{llll}
\hline Access to money (monthly income/allowance) & & \\
\hline None (ref. cat.) & - & - & 1.0 \\
\hline Less than A 10,000.00 (\$64) & -0.830 & 0.409 & $0.436^{*}$ \\
\hline A $10,000.00$ and above & -0.179 & 0.429 & 0.836
\end{tabular}

The model chi-square value $=8.006$; Hosmer-Lemeshow's significance $=0.156$

* - $\mathrm{P}<0.05$; ** - $\mathrm{P}<0.01$.; *** $-\mathrm{P}<0.001$; ref. cat. - Reference category. 
Table 2 shows that the most significant predictor of unsolicited exposure to information with sexual contents online is the time of Internet use. Young people who use the Internet all night are almost three times more likely to be exposed to unsolicited materials containing information on sex related matters. The study also shows that occasional users of the Internet are less likely to be exposed to materials con- taining information on sexuality in comparison with regular users of the Internet. Young people who have access to less than NIO 000 (\$64) monthly were found to be less likely to be exposed to unsolicited sexuality related information online. On the contrary, those who reported access monthly access to AlO 000 or more were found not to be significantly different from those without access to money.

Table 3 Online sexual activities by background characteristics (\% involved)

\begin{tabular}{|c|c|c|c|c|c|c|c|}
\hline & & $\begin{array}{l}\text { Ever } \\
\text { sent an } \\
\text { e-mail } \\
\text { with } \\
\text { sexual } \\
\text { content }\end{array}$ & $\begin{array}{l}\text { Ever visited } \\
\text { sites with } \\
\text { sexually } \\
\text { explicit } \\
\text { information }\end{array}$ & $\begin{array}{l}\text { Ever } \\
\text { discussed } \\
\text { sex related } \\
\text { issues online }\end{array}$ & $\begin{array}{l}\text { Ever involved } \\
\text { in sexually } \\
\text { stimulating } \\
\text { acts online }\end{array}$ & $\begin{array}{l}\text { Ever } \\
\text { satisfied } \\
\text { sexual urge } \\
\text { online }\end{array}$ & $\begin{array}{l}\text { Everinvolved } \\
\text { in any online } \\
\text { sexual } \\
\text { activity }\end{array}$ \\
\hline \multirow[t]{2}{*}{ Sex } & Male $(\mathrm{N}=368)$ & 18.8 & $38.9 * *$ & $25.8^{*}$ & $17.1^{* * *}$ & 4.6 & $51.6 * *$ \\
\hline & Female $(\mathrm{N}=280)$ & 17.1 & 21.4 & 20.7 & 8.6 & 3.9 & 39.3 \\
\hline \multirow[t]{3}{*}{ Age } & $10-14$ yrs $(\mathrm{N}=18)$ & $5.6 * *$ & II.I** & 16.7 & II.I & 0 & II.I*** \\
\hline & $15-19$ yrs $(N=226)$ & 12.8 & 24.8 & 21.7 & 8.8 & 4.0 & 39.4 \\
\hline & $20-24$ yrs $(N=404)$ & 21.5 & 35.9 & 25.0 & 16.1 & 4.7 & 51.7 \\
\hline \multirow{2}{*}{ Autonomy } & Living alone $(\mathrm{N}=62)$ & 29.0* & 48.4** & 30.6 & $25.8 * *$ & II.3* & $66.1 * *$ \\
\hline & Living with parents (586) & 16.9 & 29.5 & 22.9 & 12.1 & 3.6 & 44.2 \\
\hline \multirow[t]{2}{*}{ PCC } & Enjoyed PCC $(\mathrm{N}=487)$ & 17.7 & $28.5^{* *}$ & 22.4 & 12.5 & 4.1 & 44.6 \\
\hline & Never enjoyed PCC $(\mathrm{N}=\mathrm{I6I})$ & 19.3 & 39.8 & 27.3 & 16.1 & 5.0 & 51.6 \\
\hline \multicolumn{2}{|c|}{ Time of use All night user $(\mathrm{N}=174)$} & $31.6 * *$ & $48.9 * *$ & $36.8 * *$ & $23.6 * *$ & 7.5 & $68.4 * *$ \\
\hline & Day only user $(\mathrm{N}=474)$ & 13.1 & 24.9 & 18.8 & 9.7 & 3.2 & 38.2 \\
\hline \multirow{2}{*}{$\begin{array}{l}\text { Place of } \\
\text { access }\end{array}$} & Home and/or school $(\mathrm{N}=152)$ & 19.1 & 27.0 & 19.7 & 16.4 & 4.6 & 42.8 \\
\hline & Café and other places $(\mathrm{N}=496)$ & 17.7 & 32.7 & 24.8 & 12.5 & 4.2 & 47.4 \\
\hline \multirow{2}{*}{$\begin{array}{l}\text { Frequency } \\
\text { of use }\end{array}$} & Regular user $(\mathrm{N}=426)$ & $22.1 * *$ & $36.2 * *$ & $27.9 * *$ & 15.0** & 4.5 & $52.3^{*} *$ \\
\hline & Occasional user $(\mathrm{N}=222)$ & 10.4 & 22.1 & 15.3 & 10.4 & 4.1 & 34.7 \\
\hline \multirow{3}{*}{$\begin{array}{l}\text { Access to } \\
\text { money }\end{array}$} & None $(\mathrm{N}=60)$ & 11.7 & $31.7^{*}$ & $21.7^{*}$ & 15.0 & 3.3 & $40.0^{* * *}$ \\
\hline & Less than $\mathrm{Al} 0000(\mathrm{~N}=35 \mathrm{I})$ & 16.5 & 27.4 & 19.9 & 10.5 & 3.4 & 40.5 \\
\hline & Al0 000 or more $(\mathrm{N}=237)$ & 21.9 & 37.1 & 29.5 & 17.3 & 5.9 & 56.5 \\
\hline \multicolumn{2}{|l|}{$\overline{\text { All }}$} & 18.1 & 31.3 & 23.6 & 13.4 & 4.3 & 46.3 \\
\hline
\end{tabular}

Involvement in online sexual activities

Having examined unsolicited exposure to sexually explicit information, this section of the study examines young people's involvement in online sexual activities. As shown in Table 3, about 18 percent of the subjects reported that they had sent e-mails with sexual contents. Furthermore, about 31 percent of the respondents had visited sites with sexually explicit information. When asked if they had ever discussed issues relating to sex online, about 24 percent of the subjects responded in the affirmative. Table 3 shows further that 13 percent of the respondents had been involved in sexually stimulating acts online while four percent said they had satisfied themselves sexually through one online sexual activity or another. The study suggests that visiting 
websites with sexually explicit information is the most prevalent online sexual activity among young people in the Lagos metropolis. On the whole, 46 percent of the respondents had been involved in at least one of the five online sexual activities discussed. Gender is significantly associated with visiting sites with pornographic material, sex chats and involvement in sexually stimulating activities online. For these three indicators of involvement in online sexual activities, young males reported greater involvement than young females. Involvement in sending mails with sexual content, visiting sites with sexually explicit information and overall involvement in at least one online sexual activity increase with age. As shown in Table 3, living alone is associated with involvement in sending e-mails with sexual content, visiting sites with sexually explicit information, involvement in sexually stimulating acts online and satisfaction of sexual desires online, but not with involvement in sex chats.

Parent-child communication was found to be significantly associated with none but one of the online sexual activities measured in this study. As Table 3 shows, a smaller proportion of young people who had benefited from PCC reported ever visiting sites with sexually explicit information. Although for all the online sexual activities measured, young people who had benefited from PCC reported lower levels of involvement, the associations are not statistically significant. Time of Internet use is associated with involvement in online sexual activities. Of the five activities measured, the variable is associated with four, the only exception being involvement in online sexual satisfaction/gratification. While 32 percent of all-night users reported involvement in sending messages with sexual content, only 13 percent of dayonly users of the Internet had been involved in sending messages with sexual content. Close to half (49 percent) of all-night users had visited sites with sexually explicit information in comparison with a quarter of day-only users who had visited sites with sexually explicit contents. In addition, 37 percent of all-night users reported involvement in sex chats, and 24 percent reported involvement in sexually arousing activities online. On the other hand, only 19 and 10 percents of the day-only users were involved in the same activities. Approximately 68 percent of allnight users had been involved in at least one online sexual activity, while only 38 percent of day-only users had been involved in at least one of the online sexual activities measured in the study.

As shown in Table 2, there is a strong association between frequency of Internet use and involvement in online sexual activities. Involvement in online sexual activities increases with frequency of Internet use. For regular users who access the Internet weekly, involvement in sending e-mails with sexual contents, visiting sites with pornographic contents, sex chats and sexually stimulating activities are recorded as $22,36,28$ and 15 percents respectively. For occasional users on the other hand, reported involvement in these activities is $10,22,15$ and 10 percents respectively. On the whole, while more than half (52 percent) of regular young users of the Internet reported involvement in at least one of the measured online sexual activities, only 35 percent of occasional users had been involved in any of the activities.

Access to money is significantly associated with involvement in two online sexual activities. As shown in Table 2, young Internet users without access to money and those with access to ten thousand naira or more monthly reported higher rates of involvement in visiting sites with sexually explicit information and discussing sex issues online than adolescents with estimated monthly earnings below NI0 000.00. Involvement in at least one online sexual activity increases with access to money as shown in Table 3. For this composite measure, young people without access to money do not differ significantly from those with access to less than NIO 000.00. In summary, young people with monthly incomes above Al0 000.00 reported greater involvement in online sexual activities, although only two of the activities are significantly associated with access to funds.

Having explored some of the correlates of online sexual activities at the bivariate level, the study proceeds to show the predictors of involvement in at least one online sexual activity among young Internet users at the multivariate level (see Table 4). Gender, level of autonomy and parent-child communication are not significant predictors of involvement in online sexual activities. Time of Internet use was found to be associated with involvement in online sexual activities. Age as a factor is significant only for the last category, and this is so only at 0.05 level. The first two categories of adolescents are not significantly different in involvement in online sexual activities. The young adult (within the age bracket of 2024 years) is, however, almost twice as likely to be involved in online sexual activities than those within the age bracket of 10-14 (the reference category). Access to funds remains a significant predictor of involvement in online sexual activities. While adolescents with access to less than $\mathrm{N} / 0000$ a month are not significantly different from those without access to money, those who had access to NI0 000 or more in a month were found to be more likely to be involved in online sexual activities than those without access to funds. Finally, the study reveals that occasional users of the Internet are less likely to be involved in online sexual activities than frequent 
users.

Table 4 Logistic regression predicting likelihood of involvement in Online Sexual Activities (OSAs) among adolescent Internet users

\begin{tabular}{llll}
\hline Variables & B & S.E & Odds ratio \\
\hline Sex & & & \\
\hline Male (ref. cat.) & - & - & 1.0 \\
\hline Female & 0.123 & 0.088 & 0.884 \\
\hline Level of autonomy & & & \\
\hline Living alone (ref. cat.) & - & - & 1.0 \\
\hline Not living alone & -0.253 & 0.155 & 0.776
\end{tabular}

\begin{tabular}{llll}
\hline Time of Internet use & & \\
\hline Involved in all night use (ref. cat.) & - & - & 1.0 \\
\hline Not involved in all night use & -0.478 & 0.100 & $0.620^{*}$ \\
\hline
\end{tabular}

\begin{tabular}{llll}
\hline Parent child-communication & & & \\
\hline Parents discuss sexuality (ref. cat.) & - & - & 1.0 \\
\hline Parents do not discuss sexuality & 0.118 & 0.099 & 0.125 \\
\hline
\end{tabular}

\begin{tabular}{llll}
\hline Age & & & \\
\hline $10-14$ years (ref. cat.) & - & - & 1.0 \\
\hline $15-19$ years & 0.444 & 0.272 & 1.559 \\
\hline $20-24$ years & 0.657 & 0.270 & $1.928^{*}$ \\
\hline
\end{tabular}

\section{Access to money (Monthly income)}

\begin{tabular}{llll}
\hline None (ref. cat.) & - & & 1.0 \\
\hline Less than I0 000.00 & -0.122 & 0.130 & 0.885 \\
\hline N 10000.00 and above & 0,292 & 0.140 & $1.339 *$ \\
\hline & & & \\
\hline Intensity of Internet use & & & 1.0 \\
\hline Frequent users (ref. cat.) & - & - & $0.77 I^{* *}$ \\
\hline Occasional users & -0.261 & 0.091 & \\
\hline
\end{tabular}

The model chi-square value $=3.161 ;$ Hosmer-Lemeshow's significance $=0.870$

* $-\mathrm{P}<0.05$; ** $-\mathrm{P}<0.01$.; ${ }^{* * * *}-\mathrm{P}<0.00$ I; ref. cat. - Reference category.

\section{Discussion}

As expected, male youths are more exposed to sex related information on the Internet, and more involved in online sexual activities than female youths. The only exception among the variables indicating exposure to sex related information is sexual solicitation. More females reported exposure to sexual solicitation than males, as shown in this study. This shows that the societal norm that prescribes that females should not request romantic relationships, but should simply wait for the males to make the request (Oyekanmi, 2005), remains largely preserved in online interactions. Young males also reported greater involvement in online sexual activities than young females. Studies have also shown that there is greater repression on female sexuality in many societies of the world (Ollman, 1978; Tabifor, 2002, Oyekanmi, 2005). The greater involvement in online sexual activities recorded among male youths than female youths also suggests that the real life norms binding sexual and courtship behaviour remain in use even in the virtual world. In the same vein as Wolak et al. (2008), this study shows that age increases the complexity of Internet use and exposure to sex related materials. The increase in the degree of exposure to sex related information with age suggests that older adolescents and young adults use the Internet in a manner that exposes them more to information on sex and romance. The study further agrees with the studies of Wolak et al. (2008) 
and Barbovschi (2009) that as adolescents grow older, they get more involved in romantic activities online.

Exposure to sex-related information online and involvement in online sexual activities are marginally higher among young people who live alone. A factor that may be responsible for this is the absence of supervision of young people who live alone. The study further shows that young people who had not benefited from parent-child communication are more likely to be involved in online sexual activities and to be exposed to sex related information. At the multivariate level of test, however, experience of parent-child communication fails to predict involvement in online sexual activities. Wolak et al. (2007) found that young people who access the Internet at friends' homes are more involved in online sexual activities. This study could not treat as a separate group young people who access the Internet at 'friend's place' due to the small size of those who access the Internet at their friends' homes. Yet the study shows that the presence or absence of supervision that results from home/school or café use does not explain exposure to or involvement in online sexual activities. While one may expect that adolescents who access the Internet at home and school will be less exposed to and involved in online sexual activities, the study shows that the variables are not related. This suggests that in the study population, accessing the Internet at home or school does not offer any protective advantage over accessing the Internet at the café.

In order to be sure that the absence of a relationship is not a result of the fact that some of the subjects live alone, and accessing the Internet at home does not mean that parental supervision is possible, tests were conducted to see if there is an association between place of access and exposure to and involvement in online sexual activities controlling autonomy (i.e. living alone or with parents). These tests show that among young people living alone who access the Internet at home, 54 percent involvement in OSA was recorded, while 65 percent involvement was recorded among café users ( $p>0.05)$. Among home/school users and café users who live with parents, involvement levels of 38 and 43 percents respectively were recorded $(p>0.05)$. Similarly, the test on unsolicited exposure to sexuality related information shows that among young people living alone who access the Internet at home, 92 percent unsolicited exposure to sexual activities was recorded, while 76 percent unsolicited exposure was recorded among café users $(p>0.05)$. Among home/school users and café users who live alone, exposure levels of 69 and 67 percents were recorded $(p>0.05)$. Thus, the idea that accessing the Internet at home or school reduces the risk of exposure to and/or involvement in online sexual activities is disproved.

This study shows that young people with access to money are more likely to be exposed to and involved in online sexual activities than those with little or no access to money. A reason for this is that access to money increases the likelihood of spending enough time for pleasure online. A large proportion of online activities are done in cybercafés in the study population and being able to use the café is often dependent on money available to young people. This explains why access to relatively large sum of money plays a significant role in the explanation of involvement in online sexual activities. Closely related to this variable is the intensity of Internet use. The more time young people spend online, the greater their exposure to and involvement in online sexual activities. The study cannot show whether intensity of Internet use causes exposure to and involvement in online sexual activities or it is caused by them. Both are possibilities, since young people may spend more time online as a result of their involvement in online sexual activities, just as online sexual activities can keep them using the Internet regularly and for long hours. In other words, the relationship between the variables may be reversed. Adolescents involved in online sexual activities may intensify Internet use as a result of compulsivity, with implications not only for the individuals, but also for the significant others as well as the society at large (Freeman-Long, 2000). When this is the case, a situation arises in which involvement in online sexual activities fuels the desire to intensify the use of the Internet, while it is also further encouraged by intensified Internet use in a cycle.

The final and most significant predictor of exposure to information with sexual content and involvement in online sexual activities is the time of Internet use. The study has shown that young people who are day-only users of the Internet are less likely to be exposed to sexual contents online and involved in online sexual activities. When young people use the Internet all night, they have more time to spend than they may require to do the tasks for which they have decided to stay online if their primary aim is not to get involved in sexual activities online. In addition to the increased availability of time for all-night users of the Internet which may increase intensity of Internet use, online traffic is often less congested at night since there are fewer users. This makes it possible for more to be done in less time than during the day. For this reason, young adults who have paid to use the Internet all night in cafés complete their tasks sooner than they envisage while still having several hours to stay online before the expiry of the period 
for which they have paid. When this happens, young people may begin to be involved in activities such as cybering, sex chats and viewing of pornography. Finally, this study has shown that young people who are involved in online sexual activities are also exposed to unsolicited information with sexual contents online. A longitudinal study is therefore suggested to monitor which of the variables comes before the other in order to establish causation.

\section{Conclusion}

This study had the primary aim of documenting the prevalence of online sexual activities and the roles played by factors such as age, sex, autonomy, parent-child communication on matters of sexuality, allnight Internet use, place of access, access to money and intensity of Internet use in increasing or reducing young people's exposure to materials with sexual contents online, and their involvement in online sexual activities. The results of the tests show that the time of the day during which adolescents use the Internet is the strongest predictor of involvement in online sexual activities. Adolescents who use the Internet all through the night are far more likely to be involved in online sexual activities than those who use the Internet during the day only. Other predictors of exposure to and involvement in online sexual activities are intensity of Internet use, age and access to financial resources. Frequent users of the Internet are more likely to be involved in the behaviour, while young adults are also more likely to be involved in the behaviour, although older adolescents are not significantly more likely to be involved in online sexual activities than those in early adolescence.

In relation to earlier studies, these findings are important as they show a measure of convergence in the manner of influence age has on the nature of Internet use. As adolescents develop, their use of the Internet becomes more complex, the result being greater exposure to online sexual activities. It also shows that time of Internet use is a strong predictor of exposure to sexual content online and involvement in online sexual activities. It also shows that home or school Internet use does not necessarily protect young people from being exposed to sexual content online or being involved in online sexual activities. The study gives insight into the activities of young people online. The findings of the study also give an idea of how young people in other parts of the country may use the Internet as Internet penetration continues to rise. The findings of the study bring to the fore the need to educate parents and other adult care givers on factors that suggest exposure to and involvement in online sexual activities with the aim of helping them meet the needs of young people. It is important to inquire further into the nature of association between exposure to sexual content online and involvement in online sexual activities using any design that makes it possible to establish the prevalent sequence of the variables among young people.

\section{References}

Arnett, J. J. 2000. Nobody Left to Hate: Teaching Compassion after Columbine. New York: Worth.

Barbovschi, M. (2009). "Meet the "e-strangers". Predictors of Teenagers' online-offline encounters". Cyberpsychology: Journal of Psychosocial Research on Cyberspace 3, (I), Available online $h t t p: / / w w w . c y b e r p s y c h o l o g y . e u /$ view.php?cisloclanku $=200906$ l 603 \&article $=I$.

Boies, S. C., Cooper, A. and Osborne, C. 2004. "Variations in Internet-related problems and psychosocial functioning in online sexual activities: implications for social and sexual development of young adults". Cyberpsychology \& Behavior 7, (2): 207-230.

Boyd, D. and Marwick, A. 2009. "The Conundrum of visibility". Journal of Children \& Media 3, (4): 4I0-4I4.

Collins, R. L., Martino, S. and Shaw, R. 2010. "Influence of new media on adolescent sexual health: Evidence and opportunities". Rand Health Working paper.

Dombrowski, S.C., Gischlar, K.L. and Durst, T. 2007. "Safeguarding young people from cyber pornography and cyber sexual predation: a major dilemma of the Internet". Child Abuse Review 16, (3): 153-170.

Federal Ministry of Health [Nigeria] 2006. National HIV/AIDS \& Reproductive Health Survey (NARHS), 2005. Abuja: Federal Ministry of Health.

Finkelhor, D., Mitchell, J. K., and Wolak, J. 2000. Online Victimization: A Report on the Nation's Youth. Alexandria, VA: National Center for Missing and Exploited Children

Freeman-Long, R. E. 2000. "Children, Teens and Sex on the Internet". Sexual Addiction and Compulsivity 7, (I-2): $75-90$.

Kunnuji, M. 2010. The Internet and adolescent sexuality in Lagos metropolis, Nigeria. Berlin: Lambert Academic Publishing.

Longo, R. E., Brown, S. M., and Orcutt, D. P. 2002. "Effects of Internet Sexuality on Children and Adolescents" pp 87-105. In Sex and the Internet : A Guidebook for Clinicians, Edited by A. Cooper.

McFarlane, M., Bull, S. S. and Rietmeijer, C. A. 2002. "Young adults on the Internet : risk behaviours for sexually transmitted diseases and HIV". 
Journal of Adolescent Health 31, (I): I I-16.

Mitchell, K.J., Finkelhor, D, and Wolak, J. 2007.

"Online request for sexual pictures from youth: risk factors and incident characteristics". Journal of Adolescent Health 4I, (2): 196-203.

Pardun, C.J., L'Engle, K.L. and Brown, J.D. 2005. "Linking exposure to outcomes: Early adolescents' consumption of sexual content in six media". Mass Communication and Society 8, (2): 75-91.

Rambaree, K. 201 I. "Young people and cybersex in a sexually conservative society: a case study from Mauritius" pp 17I-189. In Youth culture and net culture: online social practices, Edited by $\mathrm{E}$.

Dunkels, G. Franberg, \& C. Hallgren, Doi:I0.40I8/978-I-60960-209-3.ch0I0.

Subrahmanyam, K, Smahel, D. and Greenfield, P. 2006. "Connecting development constructions to the Internet : identity presentation and sexual exploration in online teen chats rooms". Developmental Psychology 42, (3): 395- 406.

Tabifor, H. 2002. The Dignity of Human Sexuality and the AIDS Challenge. Nairobi: Alpha and Omega Publication.

United Nations Development Programme 2010. Human Development Report 2010 - The real wealth of nations: Pathways to human development. New York: Palgrave Macmillan.

West African Book Publishers 2004. Lagos Street Maps. Lagos: West African Book Publishers.

Wolak, J., Finkelhor, D. and Mitchell, K. 2004. "Internet-initiated sex crimes against minors: implications for prevention based on findings from a national study". Journal of Adolescent Health 35, 424.e I I-424.e20.

Wolak, J., Mitchell, K. and Finkelhor, D. 2007. "Unwanted and wanted exposure to online pornography in a national sample of youth Internet users" Pediatrics, II 9 (2): 247-257.

Wolak, J., Finkelhor, D., Mitchell, K. J. and Ybarra, M. L. 2008. "Online "predators" and their victims: Myths, realities, and implications for prevention and treatment". American Psychologist 63, (2): III-I 28.

World Health Organization [WHO] 200I. Sexual relations among young people in developing countries: evidence from WHO case studies. UNDP/UNFPA/World Bank Special Research Training in Human Reproduction. WHO/RHR/ 0I.8. Geneva, Switzerland: WHO.

\section{End notes}

I. The introduction of Western education delays entry into marital unions. In the absence of this institution that gives young people rights to the satisfaction of their sexual needs, they seek to meet the needs through various means including online sexual activities.

2 . Young people are often faced with the challenge of exploring their identity, i.e. answering the question: 'Who am I?' In the process, they sometimes imagine themselves as other persons. The anonymity offered by the Internet makes this possible. They act like adults and do things adults do (including involvement in romantic chats and relationships) online. 